\title{
'Meeting People Where They're At': Experiences of Family Physicians Engaging Women Who Use Illicit Drugs
}

Susan Woolhouse, MD, MClSc, CCFP

Judith Belle Brown, $P b D^{2}$

Amardeep Thind, $M D, P b D^{3}$

'South Riverdale Community Health Centre, Toronto, Ontario, Canada

${ }^{2}$ Department of Family Medicine, the Schulich School of Medicine and Dentistry and the School of Social Work, King's University College, the University of Western Ontario, London, Ontario, Canada

${ }^{3}$ Department of Family Medicine and Department of Epidemiology and Biostatistics, the Schulich School of Medicine and Dentistry, the University of Western Ontario, London, Ontario, Canada
Conflicts of interest: authors report none.

\section{CORRESPONDING AUTHOR}

Susan Woolhouse, MD, MClSc, CCFP

South Riverdale Community Health Centre 955 Queen St E

Toronto, ON M4M 3P3, Canada

swoolhouse@srchc.com

\begin{abstract}
PURPOSE There is little research exploring the experiences of family physicians caring for women who use illicit drugs. This study explores the experiences of these physicians in order to better understand the process of engaging these women in the patient-physician relationship.
\end{abstract}

METHODS We conducted a phenomenologic, qualitative study using individual, in-depth interviews with 10 family physicians working in inner-city Toronto and Ottawa, Ontario. An iterative and interpretive analysis was used.

RESULTS Three broad themes emerged from the analysis. The predominant theme was that of the patient-physician relationship, which consisted of 2 phases: the engagement phase and the maintenance phase. During the engagement phase, issues such as access and women's experiences of trauma and violence were evident and impeded participants' ability to engage with this population. As such, the patient-physician relationship during the engagement phase was tenuous. Trust and presence were paramount during this phase. Once a family physician engaged a woman, the transition to the maintenance phase was made. Within the maintenance phase, 2 subthemes were identified: continuity of care and "meeting people where they're at" (finding common ground).

CONCLUSIONS This study identified a 2-phase process of the patient-physician relationship from the perspective of family physicians caring for women using illicit drugs: the engagement and maintenance phases. Our findings identified strategies to support the patient-physician relationship during each of these phases that have implications for improving the health of these women.

Ann Fam Med 2011;9:244-249. doi:10.1370/afm.1225.

\section{INTRODUCTION}

$\mathrm{H}$ aving a strong patient-physician relationship is good for one's health. Such a relationship may be especially important for marginalized women, such as those who use illicit drugs. Despite high use of emergency departments and walk-in clinics, ${ }^{1-3}$ some studies have found marginalized women have low rates of outpatient visits and poor follow-up..$^{4-6}$ This pattern is contrary to that of women in the general population, who access the health care system more than men. ${ }^{7.9}$ Barriers these women face include spending time finding drugs, participation in sex work, homelessness, lack of health care coverage (eg, through loss of identification), mental illness, lack of transportation, discrimination from health care clinicians, and distrust of the health care system., ${ }^{4,10-17}$ This lack of continuity is of particular concern given the high morbidity and mortality in this population. ${ }^{11,15,17,18-23}$ Just as a woman's health care needs are highest, her likelihood of accessing care is lowest.

There is very little research studying the active role that family physicians can play in reducing the morbidity of women who use illicit drugs, particularly within the context of the patient-physician relationship. ${ }^{24}$ 
We speculate that higher rates of engagement in the patient-physician relationship will result in increased participation in health promotion and disease prevention activities among this population, thereby reducing morbidity.

Exploring factors that can develop and foster the patient-physician relationship can have health implications beyond the obvious benefits of a supporting relationship. This article presents the first part of a 2-part study exploring the process of building the patient-physician relationship with women who use illicit drugs.

\section{METHODS}

In this phenomenologic study, we used the qualitative method of in-depth interviews. This approach is useful when exploring a relatively narrow research question and when the experiences and understanding of the participants are the primary interest, not the broader context of that understanding. ${ }^{25}$

\section{Participant Recruitment}

Family physicians were eligible for the study if they worked in Toronto or Ottawa, Ontario, and provided care at least a half-day a week to women using illicit drugs. We used mixed sampling strategies. Once we determined that a physician met inclusion criteria, we took a maximum variation approach to ensure richness of the data (eg, form of remuneration for services, practice setting, age, sex, length of time in practice). Snowball sampling was used to obtain the names of other potential participants through personal contacts with family medicine departments, managers at community health centers, managers of harm reduction programs, and other family physicians. The principal researcher (S.W.) contacted 31 potential participants by telephone or e-mail. If they expressed an interest, they were screened to ensure they met the inclusion criteria. Twelve family physicians did not meet the inclusion criteria and 9 did not respond; therefore, the final sample was 10 family physicians. Sampling ended when saturation was achieved. ${ }^{26,27}$ We did not provide any incentive for participation.

\section{Data Collection}

One author (S.W.) conducted all of the semistructured interviews using an interview guide. The interviews, which lasted 45 to 75 minutes, took place in family physicians' offices or homes and were recorded using 2 tape recorders. All participants were asked the same open-ended question to begin the interview: "What is your experience of caring for women who use illicit drugs?" Other sample questions included (1) "What are some of the things that you do to engage these women?" and (2) "Can you describe some of the reasons that it is difficult to engage this population?" Probes were used as necessary. The author took field notes during the interview. Informed consent was obtained from all participants before each interview.

\section{Data Analysis}

The audiotaped interviews were transcribed verbatim. We analyzed the data using an iterative and interpretive process. After each interview, each researcher read the data independently to identify emerging themes. We then met to compare and combine our respective analyses looking for key words, phrases, or concepts. Common themes were manually introduced into a coding template and assigned a numerical value. These numerical codes were used to identify common themes in subsequent interviews. We continually expanded, reviewed, and revised the coding template as new themes emerged. On reaching saturation, earlier transcripts were recoded to ensure congruence with the final coding template.

Once all the data were analyzed, we identified dominant themes and condensed the coding template as some themes were identified as redundant. This iterative method of theme identification and coding is consistent with phenomenologic methods. ${ }^{27}$ There was a constant interaction between sampling, data collection, emerging analysis, and theory construction. ${ }^{27}$ Theme saturation was achieved by the sixth interview. We conducted 4 more interviews to ensure that no new themes were emerging and previous themes resonated with participants in the later interviews. This strategy is called member checking. ${ }^{28}$

We obtained ethics approval from The University of Western Ontario's Health Services Research and Ethics Board.

\section{RESULTS}

A total of 10 family physicians were interviewed. Their average age was 42 years (range, 32-58). The average time in practice was 13.5 years (range, $3.5-35$ ). Six were male. Participants worked in diverse practice settings and were remunerated in a variety of ways; however, most were paid by salary or a blended model.

The predominant theme that emerged from the data analysis was that of the patient-physician relationship in which there were 2 phases: the engagement phase and the maintenance phase.

\section{The Engagement Phase}

During the engagement phase, participants described how the structure of the primary health care system 
and the trauma-filled lives facing women limited their ability to access health care and thus, limited opportunities for engagement. Despite these barriers, participants were still able to celebrate the strong and meaningful therapeutic relationships they were able to build with their female patients who were using illicit drugs.

Participants' narratives about the relationships they formed with their patients were emotional and powerful as they struggled to meet even the most basic of patients' primary health care needs. Participants described how trust was the foundation of the patient-physician relationship. Multiple opportunities for engagement were reported as necessary before any relationship was established. This phenomenon was described by participants as a "testing period." Building trust was a very slow process:

I've seen people who...it's taken 5 years to see a doctor. So they might have seen me walk by 200 times before they decide, "Maybe I'll go see the doctor." Yeah, so it's very hard for some of them to develop trust.

Many participants believed that one of the contributing factors to this lengthy process of trust-building was that female, drug-using patients had previous "... bad experiences with the health system."

Many participants "recruited" patients by attending drop-ins and liaising with outreach workers, which allowed trust to develop vicariously: "Well it's mostly the agencies that [engage women]...so that's why I go in where I go [shelter]...they'll come and see me because their worker has brought them."

Presence was another method of establishing trust during the testing period and was a crucial feature of participants' relationships. Creating a calm presence deflected the chaos patients brought with them to their visits: "... if you can get into that... peace and serenity space...it allows them to calm down and...try to lose some of the chaos around them.... And just know that... it's safe and they're okay."

Many participants described scenarios with patients where, despite not always being able to accomplish many medical successes, they believed their mere presence was important to their patients: "But just knowing that for all their...suffering, I'm...here and they can show up and know that that's a home base." This presence was also meaningful to participants: "I derive a great deal of pleasure from some specific individuals... who I enjoy just 'cause of who they are."

Crucial to establishing trust was ensuring that patients felt respected. This theme of nonjudgmentalism was pervasive during the engagement phase: "They feel welcome. They feel that people recognize that despite their drug problems and other issues, they're sort of okay people." Participants described the need to accept their patients at face value: "I am wanting to know and to listen to their stories of pain... without judging them...so that they feel that...they are a human being...who is worthwhile."

Proving to patients that they were not going to be abandoned was also described as critical to forming a trusting physician-patient relationship. Thus, trust became the core foundation to continuity of care.

\section{The Maintenance Phase}

Once participants had engaged their female patients who used illicit drugs, the next step was maintaining that relationship. Two strategies were described as critical to maintaining the newly established relationship: continuity of care and "meeting people where they're at."

\section{Continuity of Care}

Being able to identify a person as "their doctor" was a common theme identified by participants. Continuity of care, however, looked different in participants' inner-city practices than in a more traditional practice because patient visits tended to be "in the context of some physical or mental/emotional or social crisis." There were often intense and frequent visits over short periods of time followed by extended absences: "They come in a lot. And it may just be for a moment...they become a large part of your daily... practice because you just see them every few days."

Despite the fact that many of the physicians were providing primary health care in a drop-in setting to a transient population, they all identified continuity of care as an integral component of the comprehensive care they provided. Being reliable and having a predictable schedule helped to maintain continuity of care: "The continuity is because I come to these places every week...people know that I'm pretty reliable."

Some participants felt that continuity of care was especially important when providing health care to a population of patients who had experienced recurrent loss: ". . they can't learn to trust unless there's a sustained period of time invested in them." In stark contrast to these women's frenetic and unpredictable lives, participants sought to provide a stable and consistent setting where women could come and receive primary health care, thus helping to maintain the patient-physician relationship.

\section{'Meeting People Where They're At'}

Finding common ground or, as participants described it, "meeting people where they're at," was viewed as critical to maintaining relationships with drug-using women. This idea of "not pushing too hard" was illustrated by the following scenario in which the participant was try- 
ing to figure out just how much she would be able to accomplish with her drug-using pregnant patient:

..was [it] going to be a visit where I could push ahead in terms of getting....all the things you're supposed to get done? Or...just literally "What's your weight?"... and then out the door 'cause that was all she could manage for the day.

This delicate dance of deciding when to back off and when to push forward suggested that participants were constantly reading patient cues to determine "what the patients could handle" at any given moment.

Having the patient set her own priorities rather than following a physician-driven agenda was another theme raised by many participants. In the following example, a participant recalls answering a patient's question about drinking chamomile tea while pregnant when the family physician really wanted to talk to her about the effects of smoking crack on the fetus: "... but it was a legitimate question on her part. Like that's what she wanted to hear about, so that's what I talk[ed] about." Thus, listening to patients' needs and hearing their concerns, although not an easy task, could empower women by giving them control over the decision-making processes.

\section{DISCUSSION}

This study explored the experiences of family physicians who cared for drug-using women. In particular, exploring the experiences of a group of passionate and dedicated family physicians led to rich data collection, identifying strategies that facilitate and those that hinder the development of the patient-physician relationship. One of the key findings of this study was the 2-phase process of relationship development, identified as engagement and maintenance phases. Other literature has identified similar challenges to engagement. ${ }^{24}$ Our study found early engagement to be only part of the process necessary to provide care to these women. Once early engagement had occurred, the work had just begun. Convincing women to return posed another hurdle that, if successfully addressed, would lead to the maintenance phase of the patientphysician relationship. Participants identified creative and effective strategies used to support women so that they would return for follow-up.

Our study findings support previous research that found that vulnerable populations placed particular importance on the patient-physician relationship. ${ }^{5,12,29-31}$ As in our study, factors within this relationship, such as trust, compassion, respect, and finding common ground, have been previously identified as priorities for primary health care for low-income women. ${ }^{12,30,31}$ Our study reinforces the importance of presence, trust, a nonjudgmental stance, "meeting people where they're at," and extending respect for stigmatized populations-but for the first time from the perspective of family physicians.

In examining the maintenance phase of the patientphysician relationship, our study provides new insights into the unique aspects of continuity of care in women who use drugs. O'Malley et $\mathrm{al}^{31}$ suggest that the patient-physician relationship is the "link in the chain" without which other critical aspects of primary health care such as continuity of care cannot exist. Our study was also able to elucidate some of the factors that affect continuity of care in this population. Continuity of care appeared different in these family physicians' offices-visits were often crisis-driven, brief, and intense. This pattern is in stark contrast to that in most family physicians' offices, where acute, chronic, and wellness checks predominate patient visits. In a 1992 qualitative study, Miller ${ }^{32}$ identified 3 types of clinical encounters: routine, ceremony, and drama. Routine visits were characterized by brevity and use of a biomedical model. ${ }^{32}$ Ceremonies, on the other hand, were more ritualistic, often involving the "covenantal," such as when a physician treats a patient with vitamin $B_{12}$ injections for their chronic pain. ${ }^{32(\mathrm{p} 294)}$ Finally, dramas were complicated, intense, and often involved conflict, nonadherence, or the delivery of bad news. ${ }^{32}$ Our study findings suggest a fourth type of clinical encounter: routine drama. Routine dramas were repeated visits that, although brief and frequent, were driven by constant and repetitive crises that often went unresolved.

In a review by Saultz and Albedaiwi, ${ }^{33}$ there was a consistent and noteworthy positive relationship between interpersonal continuity and patient satisfaction; however, it is unclear if this was true only for patients who sought out relationships with a family physician. Our study suggests that this may not be the case. Participants often targeted patients who were not initially interested in receiving health care services. Whether continuity of care plays a role in the initial decision of marginalized, drug-using women to seek out primary health care requires further enquiry. Findings of the current study imply that a primary health care system designed to support patient-physician relationships and promote continuity of care would improve health outcomes on many levels.

The perspectives of family physicians in this study are consistent with the perspectives of vulnerable women about the patient-physician relationship in other studies. ${ }^{5,30,31}$ It is noteworthy that for participating family physicians, establishment of trust and continuity of care looked quite different from that for family physicians in more conventional practices. The reason for this difference and the impact it may have 
on family physicians in this type of practice deserve exploration. It may be that family physicians who choose this type of work share some unique traits. Alternatively, the experience of caring for vulnerable populations such as drug-using women may change family physicians' perspectives over time. Findings from the larger 2-part qualitative study we carried out suggest that both interpretations may be true. For many family physician participants, an interest in social justice and advocacy were primary reasons for entering medical school. ${ }^{34}$ In addition, they described feeling isolated from their peers. It is possible that as women patients are more isolated, the family physicians caring for them also become more marginalized.

Our study was limited to family physicians. Given that much of the care delivered to these women is interprofessional, it would be interesting to see if other health professionals share similar experiences. This study was also limited to exploring the process of engaging women who use drugs, and it would be interesting to see if the 2-phase process is similar for drugusing men. An additional shortcoming of this study was its narrow geographic range.

Our findings imply that receiving just any primary care is not necessarily equivalent to receiving good primary care. Given that primary care of the marginalized is often fragmented (delivered by student- or volunteerrun clinics) and takes place in locations where people's living situations may be transient (eg, shelters), ${ }^{35-38}$ quantitative research comparing the impact of continuity of care in marginalized populations as compared with the general population would be important. This research may help determine if continuity of care has a greater impact on the health of drug-using women as compared with women in the general population.

In conclusion, although there is a substantial amount of literature about patient-centered care for homeless individuals, there is very little research on women using illicit drugs and, in particular, improving the health care provided to these women. This study identified a 2-phase process of the patient-physician relationship from the perspective of family physicians caring for such women: the engagement and maintenance phases. We identified strategies to support the patient-physician relationship during each of the 2 phases that have implications for improving the health of these women.

To read or post commentaries in response to this article, see it online at http://www.annfammed.org/cgi/content/full/9/3/244.

Key words: Patient-physician relationship; substance abuse; women's health; continuity of care; patient-centered care

Submitted June 24, 2010; submitted, revised, October 15, 2010; accepted November 1, 2010.
Findings from this study were presented at the North American Primary Care Research Group Annual Conference, November 15-19, 2008, Rio Grande, Puerto Rico.

Acknowledgment: The authors would like to extend their gratitude to all the family physicians who shared their stories with us.

\section{References}

1. Ottaway CA, Erickson PG. Frequent medical visits by cocaine-using subjects in a Canadian community: an invisible problem for health practitioners? J Subst Use. 1997;14(5):423-429.

2. Padgett DK, Struening EL, Andrews H, Pittman J. Predictors of emergency room use by homeless adults in New York City: the influence of predisposing, enabling and need factors. Soc Sci Med. 1995;41(4):547-556.

3. Kushell MB, Vittinghoff $E$, Hass JS. Factors associated with the health care utilization of homeless persons. JAMA. 2001;285(2):200-206.

4. Hatton DC. Homeless women's access to health services: a study of social networks and managed care in the US. Women Health. 2001;33(3/4):149-162.

5. Wie Lim Y, Anderson R, Leake B, Cunningham W, Gelberg L. How accessible is medical care for homeless women? Med Care. 2002; 40(6):510-520.

6. Weinreb L, Goldberg R, Perloff J. Health characteristics and medical service use patterns of sheltered homeless and low-income housed mothers. J Gen Intern Med. 1998;13(6):389-397.

7. Koopmans GT, Lamers LM. Gender and health care utilization: the role of mental distress and health-seeking propensity. Soc Sci Med. 2007;64(6):1216-1230.

8. Green CA, Pope CR. Gender, psychosocial factors and the use of medical services: a longitudinal analysis. Soc Sci Med. 1999;48(10): 1363-1372.

9. Malterud K. The encounter between the general practitioner and the female patients. Scand J Prim Care. 1990;8(241).

10. Roche B, Neaigus A, Miller M. Street smarts and urban myths: women, sex work, and the role of storytelling in risk reduction and rationalization. Med Anthropol Q. 2005;19(2):149-170.

11. Lewis J, Anderson RM, Gelberg L. Health care for homeless women. J Gen Intern Med. 2003;18(11):921-928.

12. Woolhouse S, Brown JB, Lent B. Women marginalized by poverty and violence: how family physicians can help. Can Fam Physician. 2004;50:1388-1394.

13. Rosenheck R, Lam JA. Client and site characteristics as barriers to service use by homeless persons with serious mental illness. Psychiatr Serv. 1997;48(3):387-390.

14. Ontario Women's Health Council. Health Status of Homeless Women: An Inventory of Issues. Ontario: Ontario Ministry of Health and Long Term Care; 2002.

15. Hwang S. Homelessness and health. CMAJ. 2001;164(2):229-233.

16. Cowan L, Hwang S, Khandor E, Mason K. The Street Health Report 2007. Toronto, ON: Street Health; 2007.

17. Usatine RP, Gelberg L, Smith MS, Lesser J. Health care for the homeless: a family medicine perspective. Am Fam Physician. 1994; 49(1):139-145.

18. Cheung A, Hwang S. Risk of death among homeless women: a cohort study and review of the literature. CMAJ. 2004;170(8): 1243-1247.

19. Galea S, Vlahov D. Social determinants and the health of drug users: socioeconomic status, homelessness, and incarceration. Public Health Rep. 2002;117(Suppl 1):S135-S145. 
20. Bassuk EL. Post-traumatic stress disorder in extremely poor women: implications for health care clinicians. J Am Med Womens Assoc. 2001;56(2):79-85.

21. Hibbs JR, Benner L, Klugman L, et al. Mortality in a cohort of homeless adults in Philadelphia. N Engl J Med. 1994;331(5):304-309.

22. Hwang SW, Lebow JM, Bierer MF, et al. Risk factors for death in homeless adults in Boston. Arch Intern Med. 1998;158(13):1454-1460.

23. Degenhardt L, Hall W, Warner-Smith M. Using cohort studies to estimate mortality among injecting drug users that is not attributable to AIDS. Sex Transm Infect. 2006;82(Suppl III):56-63.

24. Means RH. A primary care approach to treating women without homes. Med Gen Med. 2001;3(2). http://www.medscape.com/viewarticle/408938. Accessed Oct 12, 2010.

25. Crabtree BF, Miller LM, eds. Doing Qualitative Research. 2nd ed. Thousand Oaks, CA: Sage Publications; 1999.

26. Kuzel AJ. Sampling in qualitative inquiry. In: Crabtree B, Miller W, eds. Doing Qualitative Research. 2nd ed. Thousand Oaks, CA: Sage Publications; 1999.

27. Morse JM, Richards L. Readme First for a User's Guide to Qualitative Methods. Thousand Oaks, CA: Sage Publications; 2002.

28. Gilchrist VJ, Williams RL. Key informant interviews. In: Crabtree B, Miller W, eds. Doing Qualitative Research. 2nd ed. Thousand Oaks, CA: Sage Publications; 1999.

29. Goold SD, Lipkin M. The doctor-patient relationship. J Gen Intern Med. 1999;14(2):S26-S33.

30. O'Malley A, Forrest C. Beyond the examination room: primary care performance and the patient-physician relationship for low-income women. J Gen Intern Med. 2002;17(1):66-74.
31. O'Malley A, Forrest CB, O’Malley PG. Low-income women's priorities for primary care: a qualitative study. J Fam Pract. 2002;49(2): $141-146$.

32. Miller WL. Routine, ceremony, or drama: an exploratory field study of the primary care clinical encounter. J Fam Pract. 1992;34(3): 289-298.

33. Saultz JW, Albedaiwi W. Interpersonal continuity of care and patient satisfaction: a critical review. Ann Fam Med. 2004;2(5):445-451.

34. Woolhouse S. Engaging vulnerable women who use illicit drug: experiences of drug-using women and family physicians [thesis]. London, ON; The University of Western Ontario; 2009.

35. Podymow T, Turnbull J, Coyle D, Yetisir E, Wells G. Shelter-based managed alcohol administration to chronically homeless people addicted to alcohol. CMAJ. 2006;74(1):45-49.

36. Stergiopoulos V, Rouleau K, Yoder S. Shelter-based collaborative mental health care for the homeless. Psychiatr Times. 2007;24(8). http://www.psychiatrictimes.com/psychotic-affective-disorders/content/article/10168/53731. Accessed Oct 12, 2010.

37. Nuttbrock L, McQuistion H, Rosenblum A, Magura S. Broadening perspectives on mobile medical outreach to homeless people. J Health Care Poor Underserved. 2003;14(1):5-16.

38. Batra P, Chertok JS, Fisher CE, Manseau MW, Manuelli VN, Spears J. The Columbia-Harlem homeless medical partnership: a new model for learning in the service of those in medical need. J Urban Health. 2009;86(5):781-790. 